\title{
Evaluation comparison of wave amount measurement results in brass-plated tire steel cord using RMSE and cosine similarity
}

\author{
April Lia Hananto ${ }^{1}$, Sarina Sulaiman ${ }^{2}$, Sigit Widiyanto ${ }^{3}$, Aviv Yuniar Rahman ${ }^{4}$ \\ ${ }^{1,2}$ School of Computing, Universiti Teknologi Malaysia, Malaysia \\ ${ }^{1}$ Department of department of Information Systems, Universitas Buana Perjuangan Karawang, Indonesia \\ ${ }^{3}$ Faculty of Computer Science, University Gunadarma Depok, Indonesia \\ ${ }^{4}$ Department of Informatic Engineering, UniversitasWidyagama Malang, Indonesia
}

\begin{tabular}{|c|c|}
\hline Article Info & ABSTRACT \\
\hline Article history: & In the production process, quality checking is very important, one of which is \\
\hline Received Apr 1, 2020 & $\begin{array}{l}\text { on the wire. In the process of making brass-coated steel tire straps sometimes } \\
\text { produce quality goods not in accordance with the desired standard values. }\end{array}$ \\
\hline Revised Oct 6, 2020 & Checks that are carried out manually have low efficiency and quite high errors \\
\hline Accepted Dec 15, 2020 & $\begin{array}{l}\text { occur. So it is necessary to check by measuring the wavelength on the brass } \\
\text { plated steel cord automatically. In this study, used } 3 \text { automatic measurement }\end{array}$ \\
\hline Keywords: & $\begin{array}{l}\text { methods using } 2 \text { evaluations, namely RMSE and cosine similarity. The results } \\
\text { showed the best measurement using RMSE with method } 2 \text {. Whereas the worst }\end{array}$ \\
\hline $\begin{array}{l}\text { Brass-coated steel tire } \\
\text { Cosine similarity } \\
\text { RMSE }\end{array}$ & $\begin{array}{l}\text { method uses RMSE with method } 1 \text {. The smallest RMSE value is } 0.0098 \text { and } \\
\text { the largest RMSE is } 0.0966 \text {. The lowest cosine similarity value is } 0.1253 \text {, while } \\
\text { the highest cosine similarity value is } 0.2079 \text {. }\end{array}$ \\
\hline
\end{tabular}

Wave amount

This is an open access article under the CC BY-SA license.

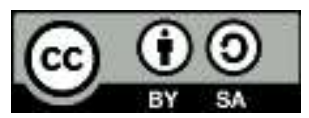

\section{Corresponding Author:}

April Lia Hananto

School of Computing

Universiti Teknologi Malaysia

Sultan Ibrahim Chancellery Building, Jalan Iman, 81310 Skudai, Johor, Malaysia

Email: aprilia@ubpkarawang.ac.id, hananto1983@graduate.utm.my

\section{INTRODUCTION}

Steel cord for tires has an important role in driving safety such as aircraft, trucks, buses or other vehicles [1]. Steel cords have weaknesses in their specific strengths, but have a high rigidity modulus and excellent thermal conductivity [2]. The low number of brass coatings has very good susceptibility to moisture and thermal aging [3]. The quality of steel cord for tires affects the stability and durability of the vehicle in steel radial tires. If the quality of the steel cord for tires is defective, it will endanger the user. In addition, quality control will automatically help companies produce good products [4]. In a wire industry itself there is a quality control section, where in this section the task is to check and measure a quality and determine whether it is marketable or not. Quality control needs to be done because brass steel cables are very prone to damage. Damage can occur due to repeated bending and tensile stresses during cutting, surface scratches, center segregation and inclusions [2]. In the process of checking and measuring this is done manually where the process uses human labor. In the quality control section is carried out by 3 shifts in 24 hours, which means 8 hours per person alternately. For this we need an automatic measuring system that can evaluate to determine a quality. Quality can be determined by measuring the wavelength. Brass steel cord produced by Bekaert Indonesia company has standard of waveamount in range 0.33-0.47. And in this design system can simplify and lighten the work in the part of quality control. 
These steel cord for tires are used in large truck tire parts, high pressure hydraulic hoses and heavy duty conveyor belts [5]. Therefore, quality control on steel cord for tires is important. Several studies have developed wire quality in various ways such as increasing coil quality factor [6], increasing wire strength but with smaller diameters [2], reducing interface adhesion factor [5], increasing conductivity, corrosion resistance and tensile strength [7]. Measurements on brass steel cord still require officer's monitoring process if using conventional measurements [8-10]. Recently, detection of wire defects in some parts of the wire such as spring-wire [11], copper wire micro-crack weld [12], wired networks [13], amorphous wire [14].

In this research, the way to control the quality is done by measuring the wavelength. This needs to be done to find out more precise measurements. The selection of image features and the similarity method accordingly become factors that influence the final result of taking an image [15]. The measurement of similarity of brass plated tire steel cord edge using the dice algorithm shows the results of $99 \%$ similarity in 29 samples by comparing image acquisition data and ground truth data [9, 10]. In measuring the number of waves of brass plated tire steel cord edge using local minima and maxima with three approaches to the number of waves method, the average measurement can be recognized as the level of accuracy and precision with the company's standard measurement values [8]. In measuring the diameter of brass palted steel cords using a vertical distance and sliding windows, there is an average difference of $0.0037 \mathrm{~mm}$. The Minimum sliding window method has a different value of about $0.0026 \mathrm{~mm}$. The third method uses the Average sliding window of about $0.0023 \mathrm{~mm}$. Quality control using the waveamount standard with the measured waveamount of brass steel cord can be done using RMSE and cosine similarity. Therefore the cosine similarity evaluation method is used. Cosine similarity is used to calculate the degree of similarity of brass-plated tire steel cords with models that are in accordance with standards. This cosine similarity calculates the cosine value between two vectors contained in a brass-plated tire steel cord [16]. It is effective for reducing the accumulation of errors [17]. Previously, the cosine similarity has applied for handwriting [18], texts [19-22], binary space [23], image [24], drift correction in gas sensor [25], an adversarial process [26]. As a comparison, the RMSE evaluation method is also used to resolve system errors [27]. As well as root mean square error (RMSE) is a calculation method that is often used in the error rate of the results of a prediction under study. Calculations that will be predicted usually produce a material consideration in a large evaluation. RMSE has been adapted in many recommendation systems [28], such as evaluating the model fit of diffusion [29], thin-film carbon Raman spectral data [30], mitigating wet bias of soil moisture ocean salinity [31], surface accuracy evaluation of large deployable mesh reflectors [32]. If the RMSE value is low, then the value of a prediction that will be generated in a model or design will be close to the value in the equation. For this reason, comparing a model or design often uses the root mean square error (RMSE) model. The purpose of this study is to make an accurate and detailed comparison of evaluation results on accurate and detailed measurements of the wave amount of brass-plated steel tire cords.

\section{RESEARCH METHOD}

In this research method has several stages of the scheme that must be done. Schematic of the research method as shown at Figure 1.

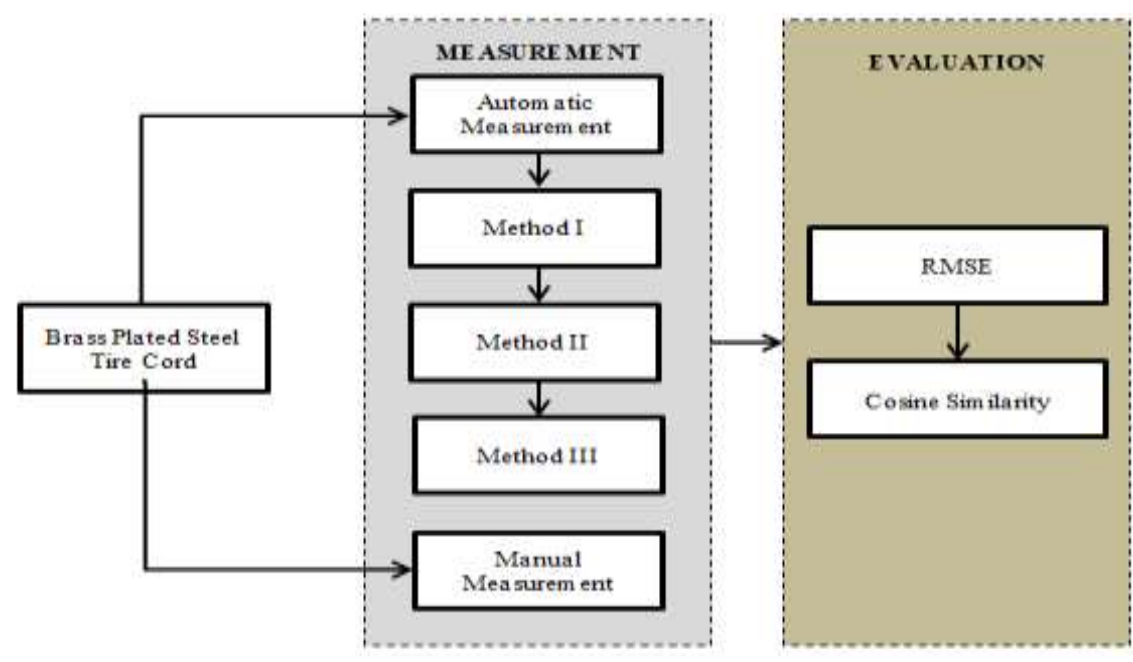

Figure 1. Comparison of evaluation of wave amount measurement results in brass-plated tire steel cord 


\subsection{Measurement}

Starting with using the system, which in this system has 3 different methods. And in the three methods will produce different values as well. Note that in all three methods using a system that measures gradually and in detail. Data is also measured manually, where in this manual measurement uses human resources in each measurement.

In Figure 2 is the process of processing a data using Method I. With this method begins by using an input value in a data that has been prepared. Then proceed with finding a value (Wa). This Wave Amount value can be the maximum and minimum value in a data to be managed. Therefore, in a maximum point and minimum point a value will be known to produce an output or final value. In Figure 3 is the process of processing a data using Method II. With this method begins by using an input value in a data that has been prepared. After that it will look for a point value $\mathrm{C} 1$ where in $\mathrm{C} 1$ this is the value ( $\mathrm{x} 1$ and $\mathrm{y} 1$ ). Then proceed to find the value of point $\mathrm{C} 2$. In $\mathrm{C} 2$ values this is the values (x2 and $\mathrm{y} 2$ ). Then proceed with finding a value (Wa).

This wave amount value can be the maximum and minimum value in a data to be managed. Therefore, in a maximum point and minimum point a value will be known to produce an output or final value. After searching for a value in C2 then looking for a center line value. Where the center line value is known between the maximum and minimum points in a graph. Then proceed with finding a value (Wa). This Wave Amount value can be the maximum and minimum value in a data to be managed. Therefore, in a maximum point and minimum point a value will be known to produce an output or final value. The process of processing a data using Method III in Figure 4.

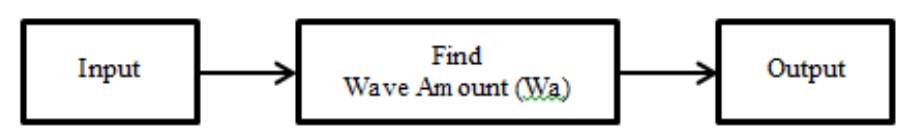

Figure 2. Method I

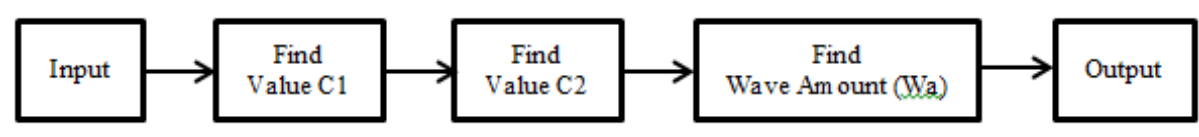

Figure 3. Method II

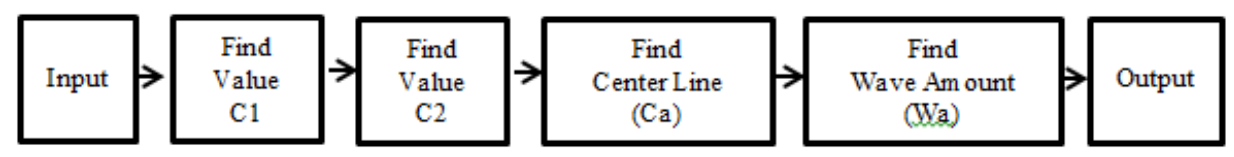

Figure 4. Method III

\subsection{Evaluation}

After manual measurements and system measurements, it will be evaluated using the root mean system error and cosine similarity methods. This evaluation will compare a result of manual measurement and system measurement. Root mean square error (RMSE) is a parameter that can be used to measure a prediction difference from a value using direct observation data. Concept in the value of root mean square error (RMSE) in the form of accuracy, the smaller the RMSE value, the higher the level of accuracy that is determined. In RMSE it is only to compare errors in observing a particular variable. But the level of calculation accuracy is more efficient and easily observed in one calculation. $n$ samples of model errors calculated as $\left(e_{i}, i=1,2, \ldots, n\right)$. RMSE calculations are formulated in the (1) [33].

$$
R M S E=\sqrt{\frac{1}{n}} \sum_{i=1}^{n} e_{i}^{2}
$$

Cosine similarity is a method of calculating cosine values that considers the degree between two vectors available in a model or design. In the calculation of this method there is no query process provided 
directly by the user. For that also the level of accuracy is not doubted in comparing data or models. The cosine similarity is a method that has an offer between two objects. Cosine similarity calculated the similarity of features. The cosine distance formula between two n-dimensional vectors is in (2) [33].

$$
\operatorname{Sim}\left(d_{j}, q\right)=\frac{\vec{d}_{j} \bullet \vec{q}}{\left|\vec{d}_{j}\right| \bullet|\vec{q}|}=\frac{\sum_{i}^{t}=1\left(W_{i} \bullet W_{i q}\right)}{\sqrt{\sum_{i}^{t}=1 W_{i j}^{2}} \cdot \sqrt{\sum_{i}^{t}=1 W_{i q}^{2}}}
$$

Where $\vec{q}_{\text {and }} \vec{d}_{j}$ is object weight. $|\vec{q}|$ and $\left|\vec{d}_{j}\right|$

is object length. When the two vectors are in the same direction, the cosine angle value takes 1 as the maximum value, and the -1 will be taken as minimum cosine angle value when the directions of the two vectors are completely opposite.

\section{RESULTS AND ANALYSIS}

Figure 5 is the result of an evaluation using RMSE with method 1. These results are obtained by measuring the height of brass-plated tire steel cord using local minima. The number of tests using a brass plated tire steel image was 29. The lowest RMSE value on the 10th image with a value of 0.0159, while the highest RMSE value on the second image with a value of 0.0966. Next in Figure 6 is the result of measuring height brass plated tire steel using method 2. From the test results it appears that the lowest RMSE value on the 14th image test with a value of 0.0098 , while the highest value on the 28 th image is 0.0730 .

The results of brass-plated tire steel cord height measurements using method 3 are shown in Figure 7. The evaluation used was using RMSE. The lowest RMSE value in image 14, while the highest RMSE value in image 13 is 0.0576 . A comparison of the results of the RMSE evaluation with the three brass-plated tire steel cord measurement methods is shown in Figure 8. Solid line is the result of the measurement evaluation using method 1 . For the star line is the result of the measurement using method 2 . While the grid line is the measurement result of method 3. The evaluation results use variation 3 the measurement method shows different results. The lowest RMSE value is in the 14th image with a value of 0.0098 . This shows that the best results when using the RMSE evaluation is method 3.

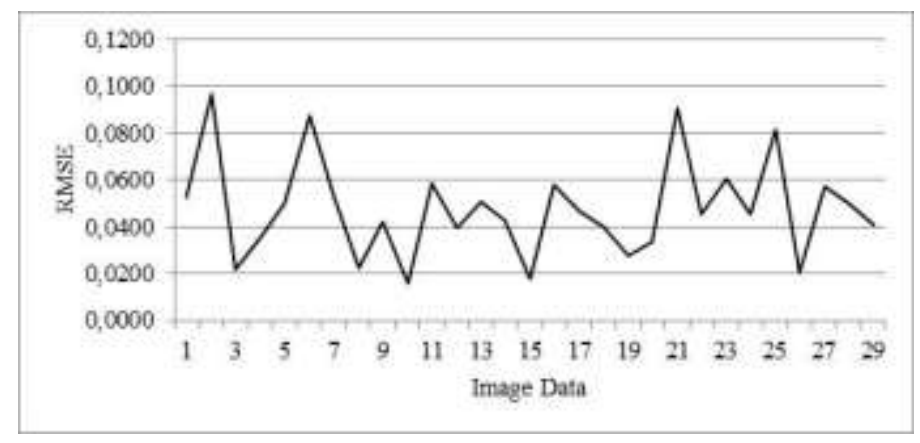

Figure 5. The result of RMSE method 1

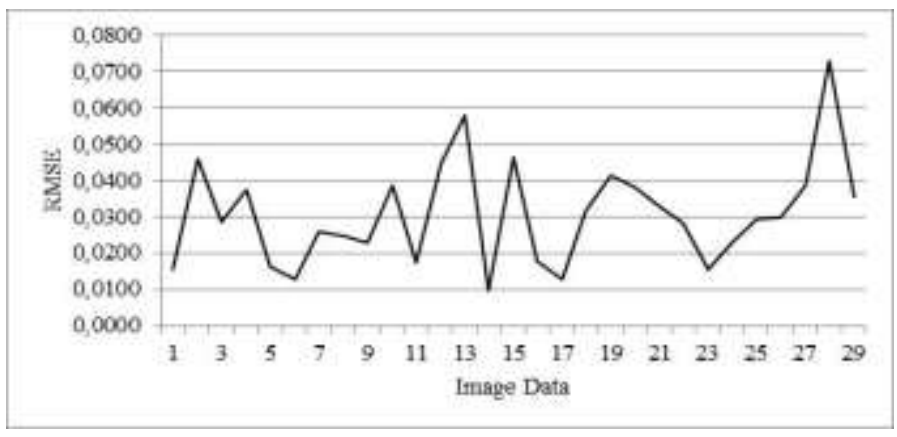

Figure 6. The result of RMSE method 2

Indonesian J Elec Eng \& Comp Sci, Vol. 22, No. 1, April 2021 : 207 - 214 


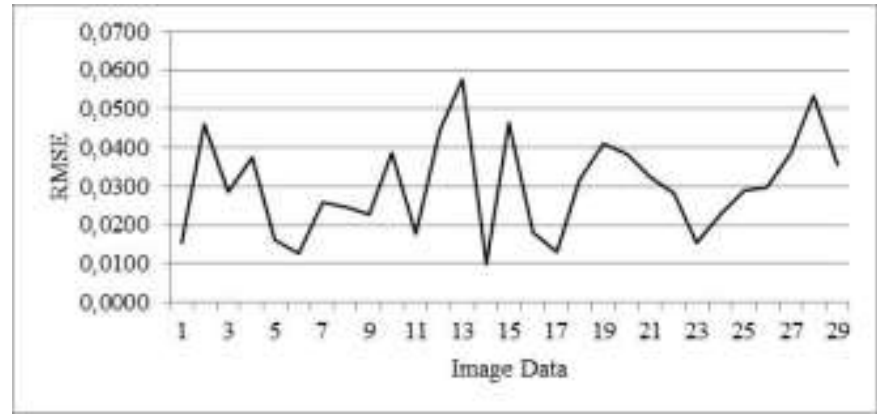

Figure 7. The result of RMSE method 3

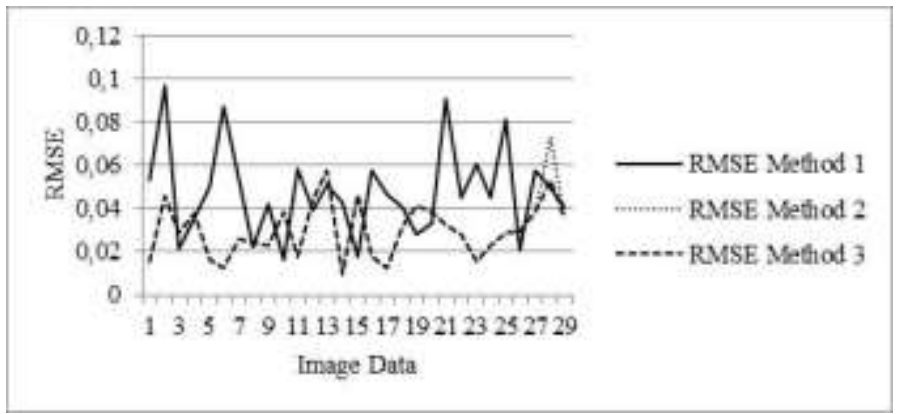

Figure 8. Comparison of evaluation RMSE

Figure 9 is an experimental result of measuring brass-plated tire steel cord height using method 1 with cosine similarity evaluation. The measurement experiment used brass-plated tire steel cord image data of 29. From the measurement results, the lowest cosine similarity value was seen in the 24th image data, while the highest cosine similarity value was in the 13th image. Likewise with method 2 shown in Figure 10 and method 3 in Figure 11 shows the results are same, the lowest cosine similarity value in the 24th image data with a value of 0.1253 and the highest in the 13th image of 0.2079 .

Comparison of evaluation using cosine similarity in Figure 12. The results of the performance of the RMSE and cosine similarity with 3 variations of the methods can be seen in Table 1 . From Table 1 it can be seen that using the RMSE method 3 has the lowest RMSE value with a value of 0.0098 . In other words, the best brass-plated tire steel cord quality is in the 14th image. While the evaluation using cosine similarity with 3 variations of methods shows the same results with the best brass-plated tire steel cord quality in the 13th image with a cosine value of 0.2079 . Evaluations using RMSE and cosine similarity show different results. If seen from the best RMSE value is approaching 0 and the best cosine similarity value is approaching 1 , then by looking at the difference of each value, it can be concluded that the best brass-plated tire steel cord is image 14. Also, it can be seen that by using 3 variations method, RMSE produces significant value differences. This means that RMSE has a large effect, while cosine similarity produces the same value from 3 variations of measurement methods. Therefore, it can be concluded that the performance of RMSE is better than cosine similarity. And from this test the best evaluation using RMSE with method 3.

Table 1. The performance of RMSE and cosine similarity with 3 variations of measurement methods

\begin{tabular}{cccc}
\hline Evaluation & Measurement Method & n-Image & Value \\
\hline RMSE & 1 & 10 & 0.0159 \\
& 1 & 2 & 0.0966 \\
& 2 & 14 & 0.0098 \\
2 & 28 & 0.0730 \\
Cosine Similarity & 3 & 14 & 0.0098 \\
& 3 & 13 & 0.0576 \\
& 1 & 24 & 0.1253 \\
& 1 & 13 & 0.2079 \\
& 2 & 24 & 0.1253 \\
& 2 & 13 & 0.2079 \\
& 3 & 24 & 0.1253 \\
& 3 & 13 & 0.2079 \\
\hline
\end{tabular}

Evaluation comparison of wave amount measurement results in brass-plated tire steel... (April Lia Hananto) 


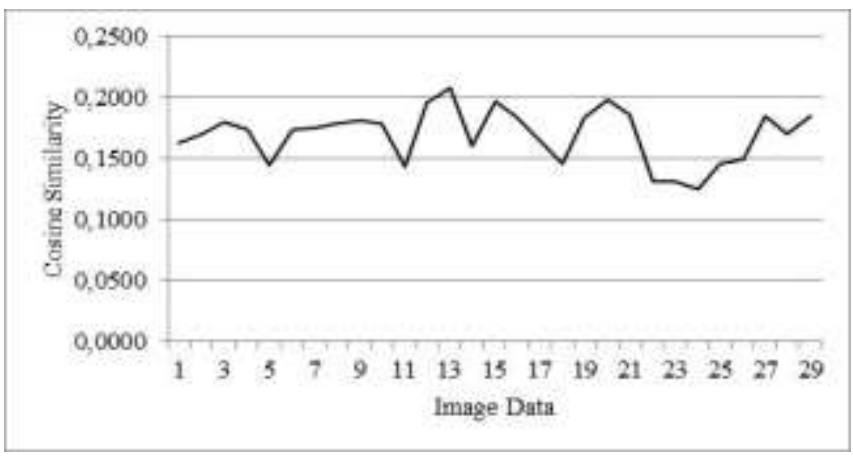

Figure 9. Evaluation result using cosine similarity 1

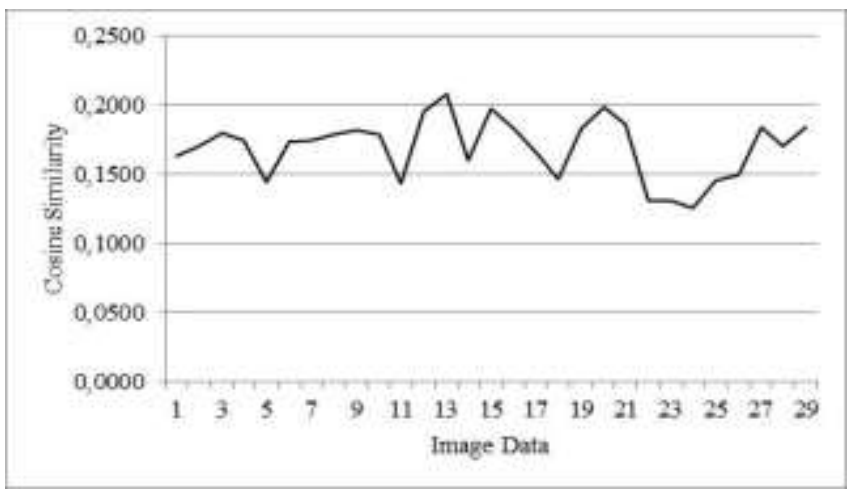

Figure 10. Evaluation result using cosine similarity 2

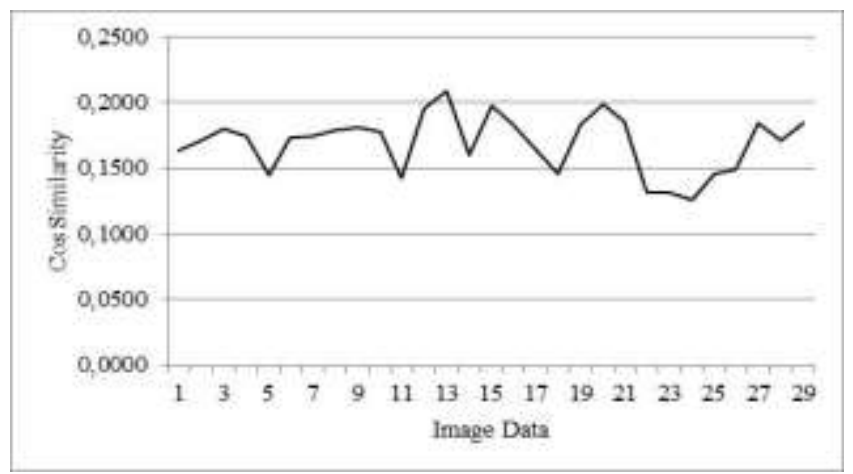

Figure 11. Evaluation result using cosine similarity 3

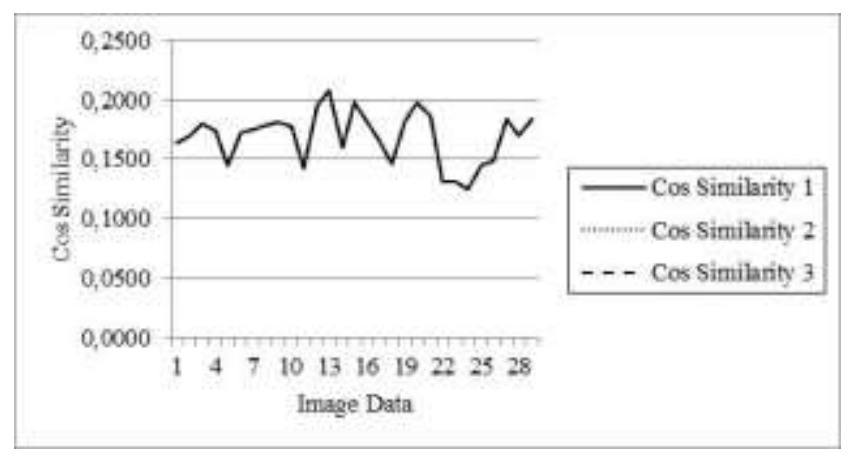

Figure 12. Comparison of evaluation using cosine similarity 


\section{CONCLUSION}

The results of the evaluation of the best wire height measurements using RMSE with method 2. Whereas the worst method uses RMSE with method 1. The smallest RMSE value is 0.0098 and the largest RMSE is 0.0966. For the evaluation of wire height measurements using cosine similarity with method 1, method 2 and method 3 with the same results. The lowest cosine similarity value is 0.1253 , while the highest Cosine Similarity value is 0.2079 . Of the two methods used are aimed at measurements that are similar to the results of manual measurements.

\section{REFERENCES}

[1] F. Auzanneau and C. Layer, "Microsecond intermittent fault detection for wire and connector defect prognostics," Proc. IEEE Sensors, vol. 2017-Decem, pp. 1-3, 2017.

[2] P. V. Minorsky, "Production Technology of Wire Rod for High Tensile Strength Steel Cord," Plant Physiol., vol. 129, no. 4, pp. 1419-1420, 2002.

[3] G. S. Jeon, "On characterizing microscopically the adhesion interphase for the adhesion between metal and rubber compound Part III. Effect of brass-plating amount for brass-plated steel cord," J. Adhes. Sci. Technol., vol. 31, no. 24, pp. 2667-2681, 2017.

[4] Z. Cheng and Y. Yang, "Design of the intelligent monitoring system for wire drawing process," 2016 13th Int. Comput. Conf. Wavelet Act. Media Technol. Inf. Process. ICCWAMTIP 2017, pp. 418-421, 2017.

[5] G. Buytaert, F. Coornaert, and W. Dekeyser, "Characterization of the steel tire cord - Rubber interface," Rubber Chem. Technol., vol. 82, no. 4, pp. 430-441, 2009.

[6] N. Sekiya and Y. Monjugawa, "A Novel REBCO Wire Structure That Improves Coil Quality Factor in MHz Range and its Effect on Wireless Power Transfer Systems," IEEE Trans. Appl. Supercond., vol. 27, no. 4, 2017.

[7] K. Piyush, A. Gautam, H. Dayal, A. Bora, C. N. Patro, and T. Sahoo, "Selection criteria for usage of aluminum wires in automobile wiring harness," 2015 IEEE Int. Transp. Electrif. Conf. ITEC-India 2015, pp. 1-5, 2016.

[8] A. Lia and S. Sulaiman, "Measurement of Wave Amount on Brass Plated Tire Steel Cord Using Local Minima and Maxima," no. 2789, pp. 2789-2796, 2020.

[9] A. L. Hananto and S. Sulaiman, "Test Similarity Data Ground Truth with Image Acquisition Using the Dice Algorithm,” no. 2782, pp. 2782-2788, 2020.

[10] A. L. Hananto, S. Sulaiman, and S. Widiyanto, "The Similarity Measurement of Brass Plated Tire Steel Cord Edge Based on Computer Vision," vol. 29, no. 6, pp. 1549-1557, 2020.

[11] X. Tao et al., "Wire Defect Recognition of Spring-Wire Socket Using Multitask Convolutional Neural Networks," IEEE Trans. Components, Packag. Manuf. Technol., vol. 8, no. 4, pp. 689-698, 2018.

[12] R. Ong and K. Y. Cheong, "Non-destructive electrical test detection on copper wire micro-crack weld defect in semiconductor device," Proc. IEEE/CPMT Int. Electron. Manuf. Technol. Symp., vol. 2016-Novem, 2016.

[13] F. Auzanneau, "Binary time domain reflectometry: A simpler and more efficient way of diagnosing defects in wired networks," AUTOTESTCON (Proceedings), vol. 2018, pp. 1-8, 2018.

[14] D. F. He and M. Shiwa, "High sensitive magnetic sensor with amorphous wire," Proc. Int. Conf. Sens. Technol. ICST, vol. 2016-March, pp. 543-545, 2016.

[15] X. Liu, G. Hu, X. Ma, and H. Kuang, "An image retrieval algorithm based on multiple convolutional features of RPN and weighted cosine similarity," Proc. 30th Chinese Control Decis. Conf. CCDC 2018, no. 61502361, pp. 4095-4098, 2018.

[16] D. Zou, Z. Liu, J. Huang, and X. Zeng, "Phased array antenna fault diagnosis based on subarray testing and cosine similarity," 2015 IEEE 12th Int. Conf. Electron. Meas. Instruments, ICEMI 2015, vol. 1, pp. 202-206, 2016.

[17] W. Minmin, S. Shengli, and L. Yejin, "A Compressive Tracking Method Based on Gaussian Differential Graph and Weighted Cosine Similarity Metric," IEEE Signal Process. Lett., vol. 25, no. 4, pp. 501-505, 2018.

[18] Y. Elfakir, G. Khaissidi, M. Mrabti, D. Chenouni, and M. Boualam, "Combined cosine-linear regression model similarity with application to handwritten word spotting," Int. J. Electr. Comput. Eng., vol. 10, no. 3, pp. $2367-$ 2374, 2019.

[19] F. Rahutomo, T. Kitasuka, and M. Aritsugi, "Semantic Cosine Similarity," Semant. Sch., vol. 2, no. 4, pp. 4-5, 2012.

[20] B. M. Yunus, M. Irfan, W. B. Zulfikar, and W. Darmalaksana, "Similarity detection for hadith of Fiqh of women using cosine similarity and boyer moore method," Int. J. Adv. Trends Comput. Sci. Eng., vol. 9, no. 1, pp. 65-73, 2020.

[21] S. Sohangir and D. Wang, "Improved sqrt-cosine similarity measurement," J. Big Data, vol. 4, no. 1, 2017.

[22] S. K. Singh, A. K. Biswal, and S. Kumar, "Social Transformation - Digital Way," vol. 836, no. October, pp. 167$182,2018$.

[23] S. Eghbali and L. Tahvildari, "Fast Cosine Similarity Search in Binary Space with Angular Multi-Index Hashing," IEEE Trans. Knowl. Data Eng., vol. 31, no. 2, pp. 329-342, 2019.

[24] L. Zhou, Y. Xiao, and W. Chen, "Imaging Through Turbid Media with Vague Concentrations Based on Cosine Similarity and Convolutional Neural Network," IEEE Photonics J., vol. 11, no. 4, 2019.

[25] A. U. Rehman, A. Bermak, and M. Hamdi, "Shuffled frog-leaping and weighted cosine similarity for drift correction in gas sensors," IEEE Sens. J., vol. 19, no. 24, pp. 12126-12136, 2019.

[26] H.-S. Heo, J. Jung, H. Shim, I.-H. Yang, and H.-J. Yu, "Cosine similarity-based adversarial process," no. July, 2019. 
[27] E. L. Veretelnikova and I. L. Elantseva, "Selection of factor for root mean square minimum error criterion," 2016 13th Int. Sci. Conf. Actual Probl. Electron. Instrum. Eng. APEIE 2016 - Proc., vol. 2, pp. 221-223, 2016.

[28] W. Wang and Y. Lu, "Analysis of the Mean Absolute Error (MAE) and the Root Mean Square Error (RMSE) in Assessing Rounding Model,” IOP Conf. Ser. Mater. Sci. Eng., vol. 324, no. 1, 2018.

[29] A. L. Schubert, D. Hagemann, A. Voss, and K. Bergmann, "Evaluating the model fit of diffusion models with the root mean square error of approximation," J. Math. Psychol., vol. 77, pp. 29-45, 2017.

[30] J. Laumer and S. K. O'Leary, “A root-mean-square-error analysis of two-peak Gaussian and Lorentzian fittings of thin-film carbon Raman spectral data," J. Appl. Phys., vol. 126, no. 4, 2019.

[31] J. H. Lee, "Using ranked probability skill score (Rpss) as nonlocal root-mean-square errors (rmses) for mitigating wet bias of soil moisture ocean salinity (smos) soil moisture," Photogramm. Eng. Remote Sensing, vol. 86, no. 2, pp. 91-97, 2020.

[32] S. Yuan, B. Yang, and H. Fang, "Direct Root-Mean-Square Error for Surface Accuracy Evaluation of Large Deployable Mesh Reflectors," no. March, 2020.

[33] T. Chai and R. R. Draxler, "Root mean square error (RMSE) or mean absolute error (MAE)? -Arguments against avoiding RMSE in the literature," Geosci. Model Dev., vol. 7, no. 3, pp. 1247-1250, 2014.

\section{BIOGRAPHIES OF AUTHORS}
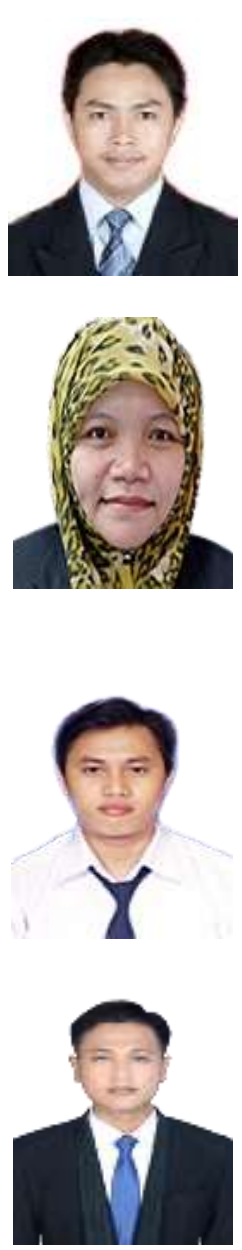

April Lia Hananto received the S.Kom. degree from STMIK Rosma in 2005 and the M.Kom. degree in 2007 from Sekolah Tinggi Teknik Informatik Benarif Indonesia. He is a chair of the Information Systems Study Program. He also as a lecturer in the Department of Information System, Buana Perjuangan Karawang University and is currently continue his Doctorate at UTM Malaysia.

Sarina Sulaiman received her Diploma and BSc in Computer Science from Universiti Teknologi Malaysia (UTM), Malaysia, MSc in Science (Multimedia System) from Universiti Putra Malaysia (UPM), Malaysia and PhD in Computer Science on Mobile Web Pre-caching Using Social Networking from UTM. Her research interests include Soft Computing, Web Caching and Prefetching in mobile apps, Web Usage Mining, Human Computer Interaction, Social Networking and Wireless Communication. She has published more than fifty research publications in journals, book chapters and conference proceedings. She has been granted as a project leader for four projects from Ministry of Science, Technology and Innovation, Malaysia, Ministry of Higher Education, Malaysia and UTM.

Sigit Widiyanto received the S.T. and M.M.S.I degree from Gunadarma University in 2011 and the M.Sc degree in 2012 from Universite De Bourgogne. He obtained his Dr. from Gunadarma University in 2017.He is a lecturer in information technology study program, Gunadarma University, Indonesia.

Aviv Yuniar Rahman received the S.T. degree from Institut Teknologi Sepuluh Nopember Surabaya in 2013 and the M.T. degree in 2017 from Institut Teknologi Sepuluh Nopember Surabaya with LPDP scholarship in 2015. He is a lecturer in the Department of Informatics Engineering, Widyagama University, Malang, Indonesia. 